\title{
Excess fructose and fatty acids trigger a model of non-alcoholic fatty liver disease progression in vitro: Protective effect of the flavonoid silybin
}

\author{
ELENA GRASSELLI $^{1}$, FRANCESCA BALDINI ${ }^{1}$, GIULIA VECCHIONE ${ }^{1}$, PAULO J. OLIVEIRA ${ }^{2}$, \\ VILMA A. SARDÃO ${ }^{2}$, ADRIANA VOCI ${ }^{1}$, PIERO PORTINCASA ${ }^{3}$ and LAURA VERGANI ${ }^{1}$ \\ ${ }^{1}$ DISTAV-Department of Earth, Environment and Life Sciences, University of Genova, I-16132 Genova, Italy; \\ ${ }^{2}$ CNC-Center for Neuroscience and Cellular Biology, University of Coimbra, 3060-197 Cantanhede, Portugal; \\ ${ }^{3}$ Division of Internal Medicine 'A. Murri', Department of Biomedical Sciences and \\ Human Oncology, University of Bari Medical School, I-70162 Bari, Italy
}

Received February 19, 2019; Accepted May 7, 2019

DOI: 10.3892/ijmm.2019.4234

\begin{abstract}
Overconsumption of fats and sugars is a major cause of development of non-alcoholic fatty liver disease (NAFLD). The main objectives of the present study were to explore the pathways sustaining the interfering metabolic effects of excess fructose and fatty acids in hepatocytes, and to clarify the mechanisms through which the nutraceutical silybin rescues the functional and metabolic alterations that are associated with the NALFD progression. Cultured hepatocytes were exposed to fructose and fatty acids, alone or in combination, to induce different grades of steatosis in vitro. Cell viability, apoptosis, free radical production, lipid content, lipid peroxidation and activity of lipogenic enzymes were assessed by spectrophotometric assays. Oxygen consumption and mitochondrial respiration parameters were measured using a Seahorse analyzer. Expression of markers for liver steatosis and dysfunction were also evaluated by reverse transcription-quantitative polymerase chain reaction. The data revealed that fructose and fatty acid combination in vitro had a positive interference on lipogenic pathways, leading to more severe steatosis and liver dysfunction, reduced cell viability, increased apoptosis, oxidative stress and mitochondrial respiration. Hepatic cell abnormalities were almost completely alleviated by silybin treatment. These findings suggest that silybin may serve as a novel and cost-effective dietary supplement for treatment and/or prevention of hepatosteatosis associated with NAFLD progression.
\end{abstract}

Correspondence to: Professor Laura Vergani, DISTAV-Department of Earth, Environment and Life Sciences, University of Genova, 26 Corso Europa, I-16132 Genova, Italy

E-mail: laura.vergani@unige.it

Key words: non-alcoholic fatty liver disease, dietary fructose, fatty acids, lipid metabolism, oxidative stress, silybin

\section{Introduction}

Overnutrition plays a pivotal role in obesity and comorbidities including nonalcoholic fatty liver disease (NAFLD), type 2 diabetes mellitus and cardiovascular disease (CVD) (1). NAFLD is characterized by hepatic accumulation of fat, particularly triglycerides (TGs), and may range from simple steatosis to nonalcoholic steatohepatitis (NASH), cirrhosis and hepatocellular carcinoma (2). In liver cells, excess TGs are stored in lipid droplets (LDs), and LD-associated proteins, such as the adipose differentiation-related protein (ADRP), regulate lipid packing and traffic (3). TG synthesis is a beneficial response against excess of potentially toxic fatty acids (FAs), leading to inflammation and reactive oxygen species (ROS) formation, particularly in mitochondria (4), which trigger lipid peroxidation of membranes acting in NAFLD progression (5).

Fructose-enriched food may contribute to the development of NAFLD (6). Fructose can enter de novo FA synthesis in liver cells through the action of fatty acid synthase (FAS). However, the extent to which fructose contributes to the metabolic disorders remains unclear, as only a limited number of data reporting its direct effects on hepatocyte during NAFLD progression are available (7).

In liver cells, NAFLD is associated with alterations in lipogenic and lipolytic pathways, which are controlled by a number of transcription factors, such as peroxisome proliferator-activated receptor (PPAR) (8), and by microRNAs (miRNAs/miRs), including miR-122, which is the most abundant hepatic miRNA (9). Dysregulation of miRNA expression has been reported in rodent models of NAFLD, and in certain cases aligned with the changes observed in obese patients with steatosis (10).

A deeper understanding of the mechanisms underlying NAFLD progression would help identifying novel cost-effective therapeutic strategies. It has been reported that plant polyphenols are promising molecules for the management of NAFLD (11). Silybin, the most relevant flavonolignan extract from the seeds of milk thistle (Silybum marianum) (12), 
exhibited certain beneficial effects in a preliminary study on NAFLD patients (13).

In the present study, an in vitro model of NAFLD progression was established to identify the pathways sustaining the interference between excess fructose and fatty acids on dysregulating lipid and radical metabolism in hepatocytes, and to verify the ability of silybin to reverse these alterations. The results may have an important translational value for possible therapy of hepatic steatosis associated with NAFLD.

\section{Materials and methods}

Cell treatments. Rat hepatoma FaO cells (European Collection of Authenticated Cell Cultures, Salisbury, UK; cat. no. 89042701) were supplied as mycoplasma-free and cultured in Coon's modified Ham's F12 with $10 \%$ fetal bovine serum (South American origin, EU-approved; Euroclone, Milan, Italy). When $80 \%$ confluence was reached, the cells were incubated in starvation medium containing $0.25 \%$ bovine serum albumin (BSA). Subsequently, cells were treated with an oleate/palmitate mixture (2:1 molar ratio; final concentration, $0.75 \mathrm{mM}$ ) for $3 \mathrm{~h}$ (referred to as the FA treatment group), with $5.5 \mathrm{mM}$ fructose for $72 \mathrm{~h}$ (Fru group), or with sequential combination of fructose for $72 \mathrm{~h}$ and FAs for $3 \mathrm{~h}$ (Fru/FA group). Cells in the Fru/FA group were then treated for $24 \mathrm{~h}$ with $50 \mu \mathrm{M}$ silybin (stock solution, $10 \mathrm{mM}$ in dimethyl sulfoxide). Silybin treatment was also performed on untreated $\mathrm{FaO}$ cells, which served as the control group.

Cell viability and apoptosis. The sulforhodamine B (SRB) assay, relying on the property of SRB to bind stoichiometrically to proteins, is used to determine cell density. Briefly, $1.5 \times 10^{4}$ cells/well were seeded in 96 -well culture plates and treated. Next, the cells were fixed and incubated with $0.5 \%$ $\mathrm{SRB}$ in $1 \%$ acetic acid for $1 \mathrm{~h}$ at $37^{\circ} \mathrm{C}$. The dye bound to proteins was extracted with $10 \mathrm{mM}$ Tris- $\mathrm{HCl}$ (pH 10), and quantified in a Varian Cary-50 Bio spectrophotometer (Agilent Technologies, Inc., Milan, Italy) (14). Caspase 3-like activity is a marker of apoptosis as it initiates DNA fragmentation (15). Caspase activity was measured in cell extracts containing $25 \mu \mathrm{g}$ proteins determined by the bicinchoninic acid method (16). Following resuspension in $20 \mathrm{mM} \mathrm{HEPES} / \mathrm{NaOH}$ ( $\mathrm{pH} 7.5$ ), $250 \mathrm{mM}$ sucrose, $10 \mathrm{mM} \mathrm{KCl}, 2 \mathrm{mM} \mathrm{MgCl}_{2}, 1 \mathrm{mM}$ EDTA, $2 \mathrm{mM}$ dithiothreitol (DTT) and $100 \mu \mathrm{M}$ phenylmethylsulfonyl fluoride, the cell extracts were incubated for $1 \mathrm{~h}$ at $37^{\circ} \mathrm{C}$ in $25 \mathrm{mM}$ HEPES (pH 7.5), 10\% sucrose, $10 \mathrm{mM}$ DTT, $0.1 \%$ CHAPS and $100 \mu \mathrm{M}$ caspase substrate Ac-DEVD-pNA. The released pNA was measured spectrophotometrically, and the results are expressed as nmol of pNA released per $\mu \mathrm{g}$ of protein (17).

Lipid quantification and imaging. TGs were extracted from the different cell groups and spectrophotometrically quantified as previously described (18). Data are expressed as the percent TG content relative to the control group. For LD visualization, cells growing on coverslips were treated as aforementioned, rinsed with PBS, fixed with 4\% paraformaldehyde, stained by Oil Red O (19) and then examined with a Leica DMRB light microscope equipped with a Leica CCD camera DFC420C (Leica, Wetzlar, Germany).
FAS activity. FAS activity in the different cell groups was measured according to Goodridge (20). Briefly, cell lysate was obtained by mixing cells with $0.1 \mathrm{M} \mathrm{KPi} \mathrm{(pH} \mathrm{7.0),} 3 \mathrm{mM}$ EDTA and $1 \mathrm{mM}$ DTT via a syringe needle. Then $20 \mu \mathrm{g}$ of lysate were mixed to $0.1 \mathrm{M} \mathrm{KPi}(\mathrm{pH} 7.0), 0.025 \mathrm{mM}$ acetyl coenzyme A (CoA), $0.2 \mathrm{mM}$ NADPH, $3 \mathrm{mM}$ EDTA, $1 \mathrm{mM}$ DTT, $25 \mathrm{mg} / \mathrm{ml} \mathrm{BSA}$ and $0.1 \mathrm{mM}$ malonyl-CoA. NADPH disappearance was followed by spectrophotometric examination. FAS activity (nmol NADPH/min $/ \mathrm{mg}$ protein) was expressed as the percentage relative to the control group.

ROS production and lipid peroxidation. ROS production was quantified through the oxidation of 2',7'-dichlorofluorescin diacetate (DCF-DA; Fluka, Germany) to 2',7'-dichlorofluorescein (DCF), which was measured using a LS50B fluorimeter (PerkinElmer, Inc., Waltham, MA, USA). Briefly, suspended cells were loaded with $10 \mu \mathrm{M} \mathrm{DCF-DA}$ at $37^{\circ} \mathrm{C}$ in the dark, centrifuged (800 x g for $10 \mathrm{~min}$ at $4^{\circ} \mathrm{C}$ ) and resuspended in PBS (21). The fluorescent intensity was normalized to the protein content. Lipid peroxidation was then evaluated through the thiobarbituric acid reactive substance assay, as previously described (22). Cells were incubated for $45 \mathrm{~min}$ at $95^{\circ} \mathrm{C}$ with 2 vol thiobarbituric acid (TBA) solution, containing $0.375 \%$ TBA, $15 \%$ trichloroacetic acid and $0.25 \mathrm{~N} \mathrm{HCl}$. Subsequently, 1 vol N-butanol was added, and the absorbance of the organic phase was measured. Values [pmol of malondialdehyde (MDA) per $\mathrm{ml} / \mathrm{mg}$ protein] were expressed as the percentage relative to the controls.

$R N A$ extraction and reverse transcription-quantitative polymerase chain reaction $(R T-q P C R)$. Total RNA was extracted using TRIzol reagent (Thermo Fisher Scientific, Inc., Milan, Italy) and quantified spectrophotometrically. Then, cDNA was synthesized by using RevertAid H Minus transcriptase according to manufacturer's instructions (Thermo Fisher Scientific, Inc.); qPCR was performed in quadruplicate using 1X IQ ${ }^{\mathrm{TM}}$ SYBR $^{\circledR}$ Green SuperMix and a Chromo4 ${ }^{\mathrm{TM}}$ system (Bio-Rad Laboratories, Inc., Milan, Italy) (23). Primer pairs for the assessed genes were designed ad hoc starting from the coding sequences of Rattus norvegicus (http://www.ncbi.nlm. nih.gov/Genbank/GenbankSearch.html) and listed in Table I. The amplification conditions were as follows: $3 \mathrm{~min}$ at $95^{\circ} \mathrm{C}$, followed by 40 cycles consisting of $5 \mathrm{sec}$ at $95^{\circ} \mathrm{C}, 30 \mathrm{sec}$ of annealing (temperatures listed in Table I), and $40 \mathrm{sec}$ of extension at $72^{\circ} \mathrm{C}$. At the end, a melting curve ranging between 55 and $95^{\circ} \mathrm{C}$ was measured. The relative quantity of target mRNA was calculated by using the comparative $\mathrm{Cq}$ method and was normalized for the expression of GAPDH gene (24).

In order to measure miR-122 expression, the High-Capacity cDNA RT kit and the miRNA-specific primers provided with the TaqMan MicroRNA Assay kit (Thermo Fisher Scientific, Inc.) were used. Amplification was performed using the StepOnePlus Real-Time PCR system (Thermo Fisher Scientific, Inc.). Probe and primers for miR-122-5p (4427975-002245) and miRNA U6 (4427975-001973) were provided by Thermo Fisher Scientific, Inc. The relative expression of miR-122 and mRNAs was calculated by the comparative $\mathrm{Cq}$ method using miRNA U6 and GAPDH as housekeeping genes (24).

Oxygen consumption. Oxygen consumption was measured using the Seahorse XFe96 Extracellular Flux analyzer 
Table I. Primer sequences table.

\begin{tabular}{|c|c|c|c|c|}
\hline Gene & Forward primer & Reverse primer & $\begin{array}{c}\text { Annealing } \\
\text { temperature } \\
\left({ }^{\circ} \mathrm{C}\right)\end{array}$ & Accession ID \\
\hline ADRP & CCGAGCGTGGTGACGAGGG & GAGGTCACGGTCCTCACTCCC & 64 & AAH85861 \\
\hline GAPDH & GACCCCTTCATTGACCTCAAC & CGCTCCTGGGAAGATGGTGATGGG & 60 & DQ403053 \\
\hline IKBIP & CAGAACAGTGAGCAGGCAAG & ACGGCATTCTCTATGGTTGG & 60 & NM_001009430.2 \\
\hline PPAR $\alpha$ & CCCCACTTGAAGCAGATGACC & CCCTAAGTACTGGTAGTCCGC & 60 & NM_013196 \\
\hline $\operatorname{PPAR} \gamma$ & CGGAGTCCTCCCAGCTGTTCGCC & GGCTCATATCTGTCTCCGTCTTC & 60 & Y12882 \\
\hline PPAR & AATGCCTACCTGAAAAACTTCAAC & TGCCTGCCACAGCGTCTCAAT & 60 & AJ306400.1 \\
\hline CPT1 & CCGCTCATGGTCAACAGCA & CAGCAGTATGGCGTGGATGG & 60 & NM_031559 \\
\hline $\mathrm{UCP} 2$ & CGTCGGACCTAGCCGTCTGCA & CGGAGTCGGGAGGGTGCTTTG & 56 & ВС062230 \\
\hline
\end{tabular}

ADRP, adipose differentiation-related protein; IKBIP, inhibitor of nuclear factor- $\mathrm{kB}$ kinase subunit $\beta$-interacting protein; PPAR, peroxisome proliferator-activated receptor; CPT1, carnitine palmitoyltransferase 1; UCP2, uncoupling protein 2.

(Agilent Technologies, Inc., Santa Clara, CA, USA) as previously described (25). Briefly, approximately $2 \times 10^{4}$ cells/well were seeded into 96-well plates. A final concentration of $3 \mu \mathrm{M}$ oligomycin, $1 \mu \mathrm{M}$ FCCP, and a mixture of $1 \mu \mathrm{M}$ rotenone and $1 \mu \mathrm{M}$ antimycin were added sequentially to cells. The sensor cartridge and the calibration plate were used for calibration. Three baseline rate measurements of oxygen consumption rate (OCR) were made using a 3-min mixing and 3-min measure cycle. The compounds were injected pneumatically by the Seahorse XFe96 analyzer into each well and mixed, following which the OCR measurements were conducted using the 3-min mixing and 3-min measure cycle (26).

Statistical analysis. Data are expressed as the mean \pm standard deviation of at least three independent biological experiments performed as technical triplicates. Statistical analysis was performed using analysis of variance with Tukey's post-test (GraphPad Software, Inc., San Diego, CA, USA). Differences with $\mathrm{P} \leq 0.05$ values were considered as statistically significant.

\section{Results}

Excess FAs and fructose alter lipid metabolism and cell function. The extent of steatosis was assessed by Oil Red O staining and TG quantification. The steatosis features were assessed in terms of the accumulation of cytosolic LDs, whose number and size markedly increased in all steatotic cells compared with the control cells (Fig. 1A). As shown in Fig. 1B, quantification of intracellular TGs revealed that fructose and fatty acids alone increased the TG content by $57 \%(\mathrm{P} \leq 0.01)$ and $87 \%(\mathrm{P} \leq 0.001)$, respectively, compared with the control group, while their combination (Fru/FA) led to a larger increase of $277 \%$ vs. the control group ( $\mathrm{P} \leq 0.001)$. As markers for $\mathrm{LD}$ accumulation and hepatic cell dysfunction, the mRNA expression levels of ADRP and inhibitor of nuclear factor- $\kappa \mathrm{B}$ kinase subunit $\beta$-interacting protein (IKBIP), respectively, were then assessed (Fig. 1C). ADRP expression was upregulated by FAs alone (1.85-fold induction vs. control; $\mathrm{P} \leq 0.001)$, with even greater upregulation induced by the Fru/FA combination (2.08-fold induction vs. control; $\mathrm{P} \leq 0.001$ ). However, IKBIP expression was significantly upregulated only by the Fru/FA combination (1.61-fold induction vs. control; $\mathrm{P} \leq 0.001$ ). Furthermore, it was observed that Fru alone, but not FAs, stimulated the FAS activity by $125 \%$ as compared with the control group ( $\mathrm{P} \leq 0.05)$, whereas the Fru/FA combination markedly reduced this Fru-induced activity by $59 \%$ (vs. Fru group; P $\leq 0.05$; Fig. 1D). On the other hand, the expression of miR-122 showed a significant increase only in Fru/FA-treated cells (1.52-fold induction vs. control; $\mathrm{P} \leq 0.05$; Fig. 1E).

Lipid peroxidation was also assessed as a marker of oxidative stress. The MDA level increased by 89 and $67 \%$ in response to FAs alone and Fru/FA combination, respectively, as compared with the control group ( $\mathrm{P} \leq 0.001$; Fig. $1 \mathrm{~F})$. This oxidative imbalance was paralleled by changes in caspase 3-like activity, which increased in cells exposed to FAs alone or Fru/FA combination $(+142$ and $+145 \%$ vs. control, respectively; $\mathrm{P} \leq 0.001$; Fig. $1 \mathrm{G})$. By contrast, cell viability did not change in FA cells, but it was significantly reduced by $13 \%$ in cells exposed to Fru alone as compared with the control cells $(\mathrm{P} \leq 0.01)$, and further reduced by $23 \%$ in the Fru/FA combination group vs. the control $(\mathrm{P} \leq 0.01$; Fig. $1 \mathrm{H})$.

Silybin counteracts the steatogenic effects of fructose and FAs. Exposure of Fru/FA cells to $50 \mu \mathrm{M}$ silybin for $24 \mathrm{~h}$ markedly reduced the steatosis grade by $35 \%$ of $\mathrm{TG}$ content $(\mathrm{P} \leq 0.01)$, and the IKBIP upregulation by $32 \%(\mathrm{P} \leq 0.001)$ compared with Fru/FA cells (Fig. 2A and B). However, silybin did not change the ADRP mRNA level (Fig. 2C). Moreover, silybin treatment led to changes in the lipogenic transcription factor PPAR $\gamma$, whose expression was upregulated in Fru/FA cells (1.55-fold induction vs. control; $\mathrm{P} \leq 0.01)$ and reduced by $67 \%$ upon silybin treatment with respect to Fru/FA (P $\leq 0.001)$; by contrast, PPAR $\alpha$

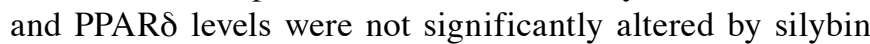
(Fig. 2D). Exposure to silybin further increased miR-122 expression (1.84-fold induction vs. control; $\mathrm{P} \leq 0.001)$ in Fru/FA cells, in which this miRNA was already overexpressed (Fig. 2E). Treatment of control cells with silybin had no effects on the expression of these genes (data not shown).

Silybin counteracts apoptosis and mitochondrial dysfunction . Silybin treatment did not rescue the reduction in cell viability 
A

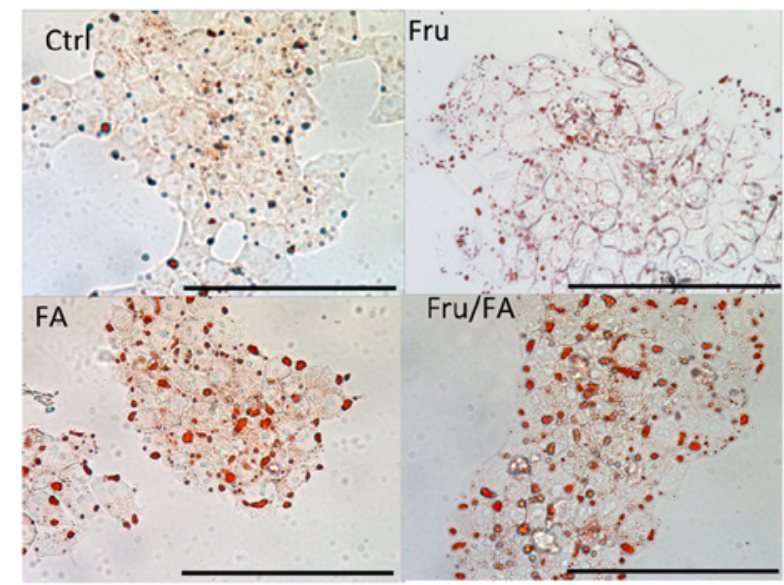

$\mathrm{B}$

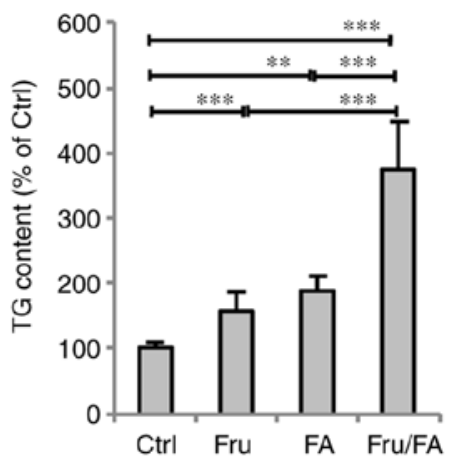

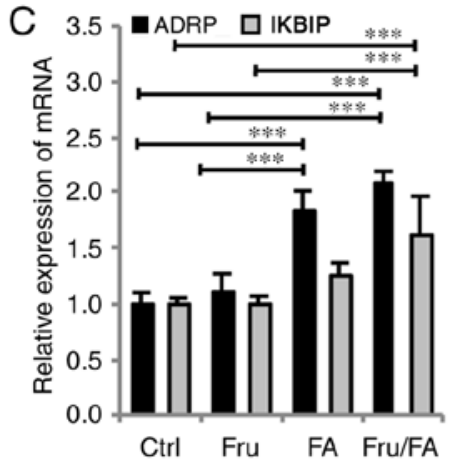

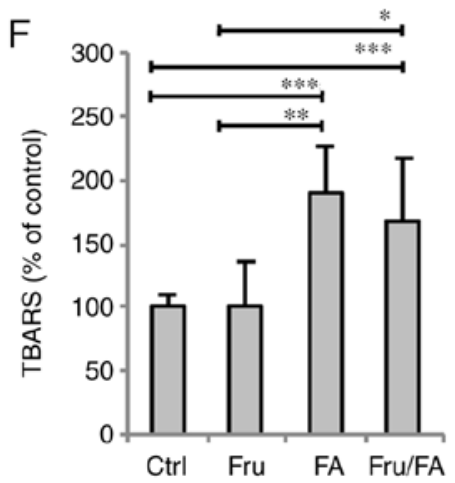

D

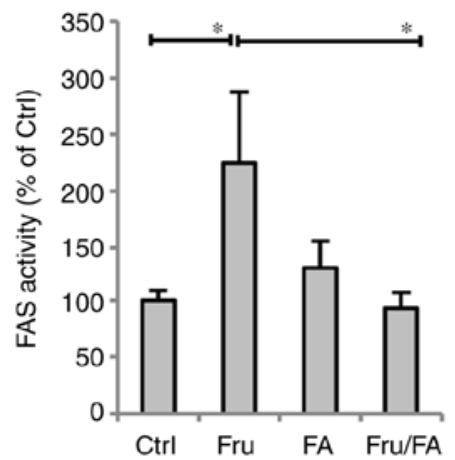

G

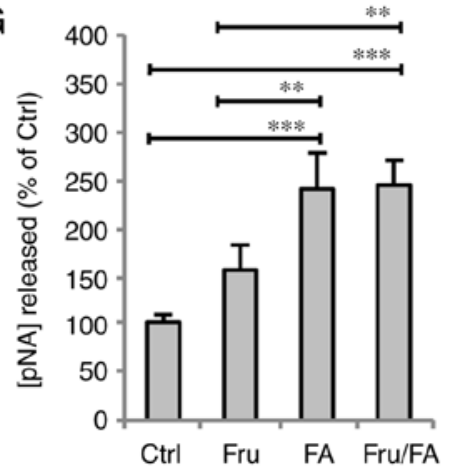

E

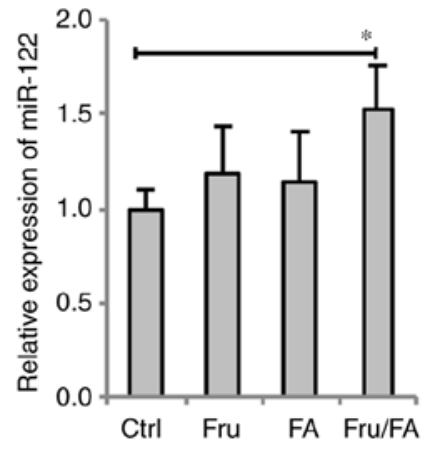

$\mathrm{H}$

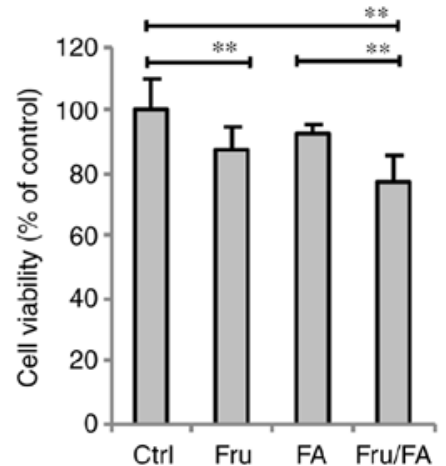

Figure 1. Steatogenic effects of Fru, FAs and their combination ( Fru/Fa) in $\mathrm{FaO}$ cells. (A) Lipid droplet accumulation was visualized by Oil Red $\mathrm{O}$ staining (magnification, x40; bar, $100 \mu \mathrm{m}$ ). (B) TG content was quantified spectrophotometrically and normalized to total protein level. (C) Expression levels of ADRP and IKBIP mRNA were evaluated by RT-qPCR and expressed as the fold induction relative to the control. (D) FAS activity (nmol NADPH/min/mg protein) was quantified spectrophotometrically. (E) miR-122 expression was evaluated by RT-qPCR using U6 as the internal control and is expressed as the fold induction relative to the control. (F) Malondialdehyde level (pmol MDA/ml/mg protein) was quantified by TBARS assay. (G) Activity of caspase 3 (nmol of pNA released $/ \mu \mathrm{g}$ protein) was measured spectrophotometrically. $(\mathrm{H})$ Metabolic activity was measured by sulforhodamine B assay (percentage relative to the controls). All values are expressed as the mean \pm standard deviation from at least three independent experiments. ${ }^{*} \mathrm{P} \leq 0.05$, ${ }^{* *} \mathrm{P} \leq 0.01$ and ${ }^{* * *} \mathrm{P} \leq 0.001$. Fru, fructose; FA, fatty acid; Ctrl, control; TG, triglyceride; ADRP, adipose differentiation-related protein; IKBIP, inhibitor of nuclear factor- $\kappa \mathrm{B}$ kinase subunit $\beta$-interacting protein; RT-qPCR, reverse transcription-quantitative polymerase chain reaction; FAS, fatty acid synthase; TBARS, thiobarbituric acid reactive substance.

caused by Fru/FA, but it had anti-apoptotic effects as indicated by the decrease in the caspase 3 -like activity by $38 \%$ compared with the Fru/FA cells ( $\mathrm{P} \leq 0.001$; Fig. $3 \mathrm{~A}$ and B). Silybin was also able to counteract the lipid peroxidation (reduction by $30 \%$ as compared with Fru/FA; $\mathrm{P} \leq 0.05$ ) and the ROS levels (reduction by $50 \%$ as compared with Fru/FA; P $\leq 0.001$; Fig. 3C and D) associated with excess fat in Fru/FA cells.

Steatotic hepatocytes typically stimulate respiration and ATP production in an attempt to counteract the excess TGs (21). Silybin reduced basal respiration by $56 \%$ ( $\mathrm{P} \leq 0.01)$, maximal respiration by $62 \%(\mathrm{P} \leq 0.001)$ and ATP production by $60 \%$ $(\mathrm{P} \leq 0.001)$ in Fru/FA cells, without significant effects on proton leak (Fig. 4A-D). Moreover, the expression of the mitochondrial proteins carnitine palmitoyltransferase 1 (CPT1) and uncoupling protein 2 (UCP2), which is the main regulatory step of mitochondrial FA oxidation, was increased in Fru/FA cells (2.29- and 1.74-fold induction, respectively, vs. control; $\mathrm{P} \leq 0.001$ and $\mathrm{P} \leq 0.01)$. Further upregulation to the CPT1 and UCP2 levels by 68 and $50 \%$, respectively, was observed upon exposure to silybin ( $\mathrm{P} \leq 0.001$ for both; Fig. 4E). Treatment of control cells 

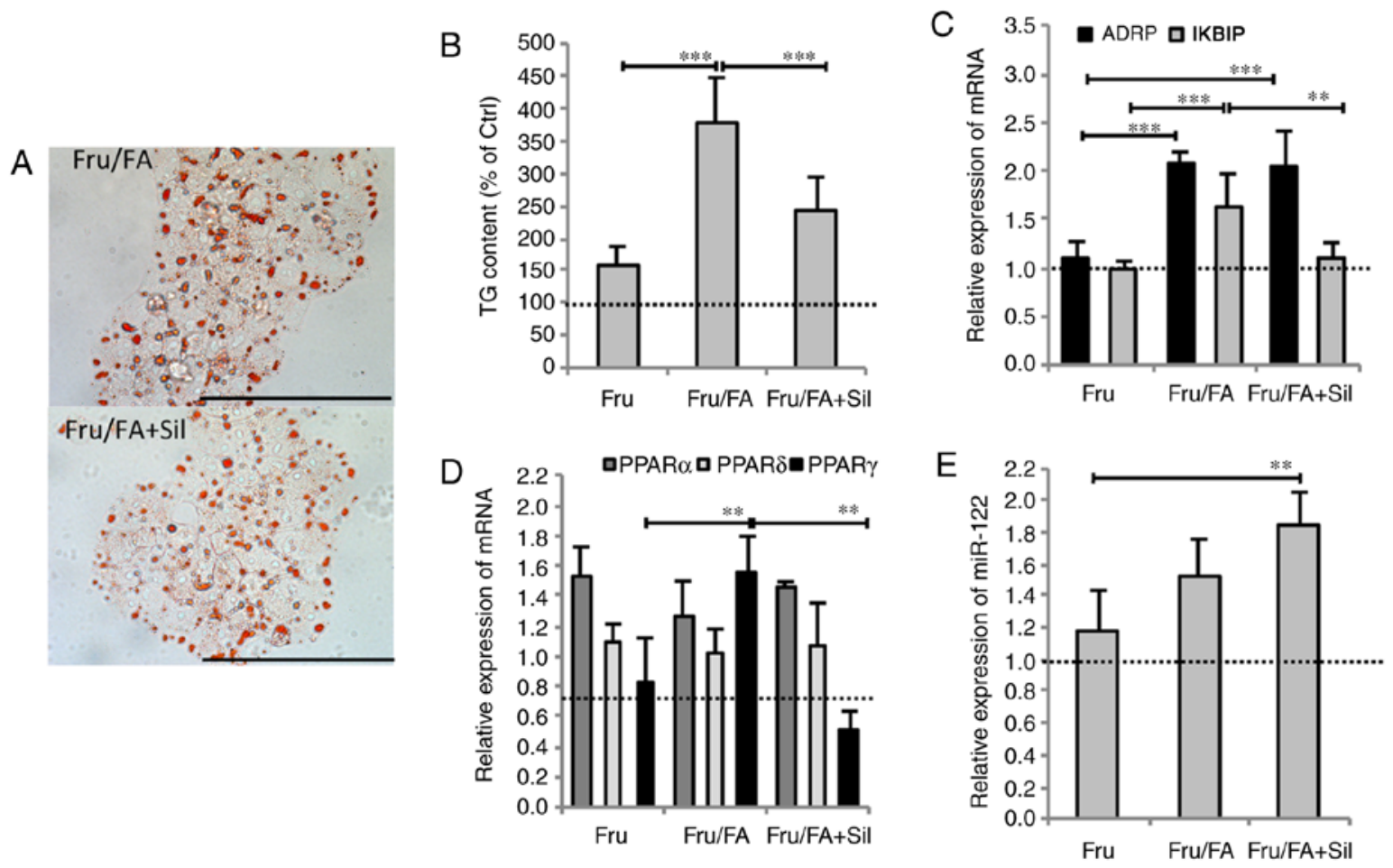

Figure 2. Silybin counteracts lipid metabolism dysregulation. Cells incubated with Fru/FA were then treated for $24 \mathrm{~h}$ with $50 \mu \mathrm{M}$ silybin. (A) Microphotographs of Oil Red O-stained cells at a magnification of x40 (bar, $100 \mu \mathrm{m}$ ), and (B) histogram of TG content. (C) mRNA expression levels of ADRP and IKBIP, (D) mRNA expression levels of PPAR $\alpha, \gamma$ and $\delta$, and (E) miR-122 expression. All values are expressed as the mean \pm standard deviation from at least three independent experiments. ${ }^{* *} \mathrm{P} \leq 0.01$ and ${ }^{* * * *} \mathrm{P} \leq 0.001$. Fru, fructose; FA, fatty acid; TG, triglyceride; ADRP, adipose differentiation-related protein; IKBIP, inhibitor of nuclear factor- $\mathrm{\kappa B}$ kinase subunit $\beta$-interacting protein.
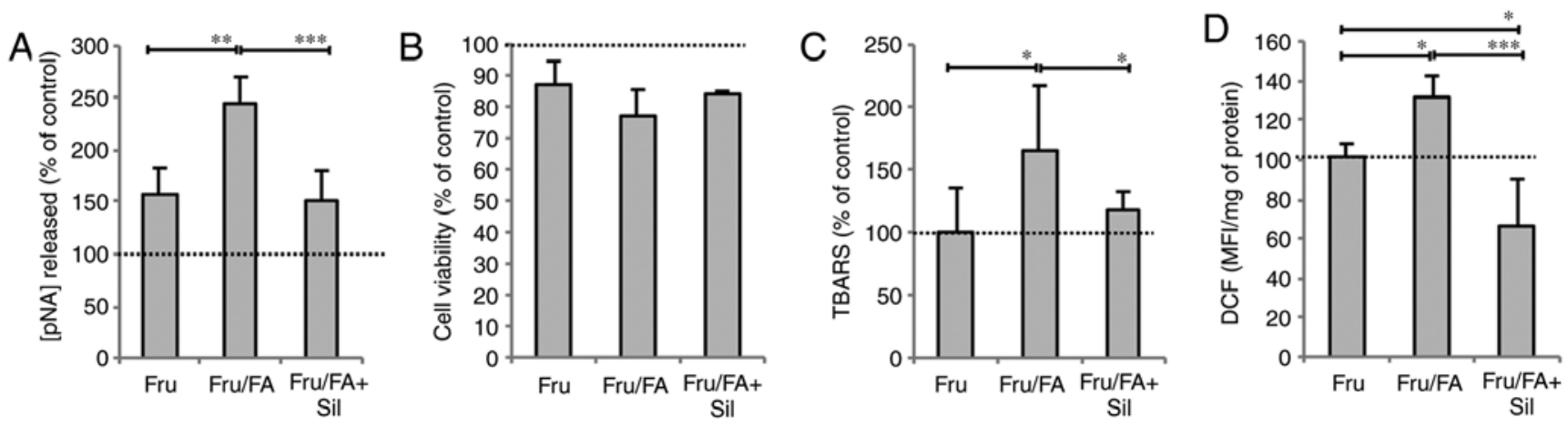

Figure 3. Silybin counteracts the cell viability and oxidative stress. Cells incubated with Fru/FA were then treated with silybin. (A) Activity of caspase 3 . (B) Metabolic activity measured by sulforhodamine B assay, indicating the cell viability. (C) Malondialdehyde level was quantified by TBARS assay. (D) Intracellular level of reactive oxygen species was quantified fluorimetrically. All values are expressed as the mean \pm standard deviation from at least three independent experiments. ${ }^{*} \mathrm{P} \leq 0.05,{ }^{* *} \mathrm{P} \leq 0.01$ and ${ }^{* * *} \mathrm{P} \leq 0.001$. Fru, fructose; FA, fatty acid; TBARS, thiobarbituric acid reactive substance.

with silybin had no effects on apoptosis, lipid peroxidation and mitochondrial respiration (data not shown).

\section{Discussion}

The present study provided insights into the molecular mechanisms through which excess fructose impairs the lipogenic pathways in hepatocytes. In the past, fructose was considered as a beneficial dietary component since it does not stimulate insulin secretion; however, the harmful effects of fructose have recently gained mainstream attention. Studies have reported that high fructose intake stimulates de novo lipogenesis (27), and mice fed a diet of fats and high-fructose corn syrup developed equally severe NAFLD (28). The findings of the present study revealed that exposure of $\mathrm{FaO}$ cells to a fructose/fatty acid combination led to larger TG synthesis and accumulation as compared with the single agents. In addition, it was observed that the more severe steatosis was associated with worsening of cell dysfunction parameters, including cell viability, oxidative stress and mitochondrial respiration.

In the cell model of the current study, the sequential exposure of hepatocytes to high fructose and fatty acids mimics the NAFLD progression in vitro. Excess fructose alone stimulates FAS activity resulting in TG overproduction, and Fru/FA combination led to more severe cell dysfunction compared with the single treatments, as confirmed by the 

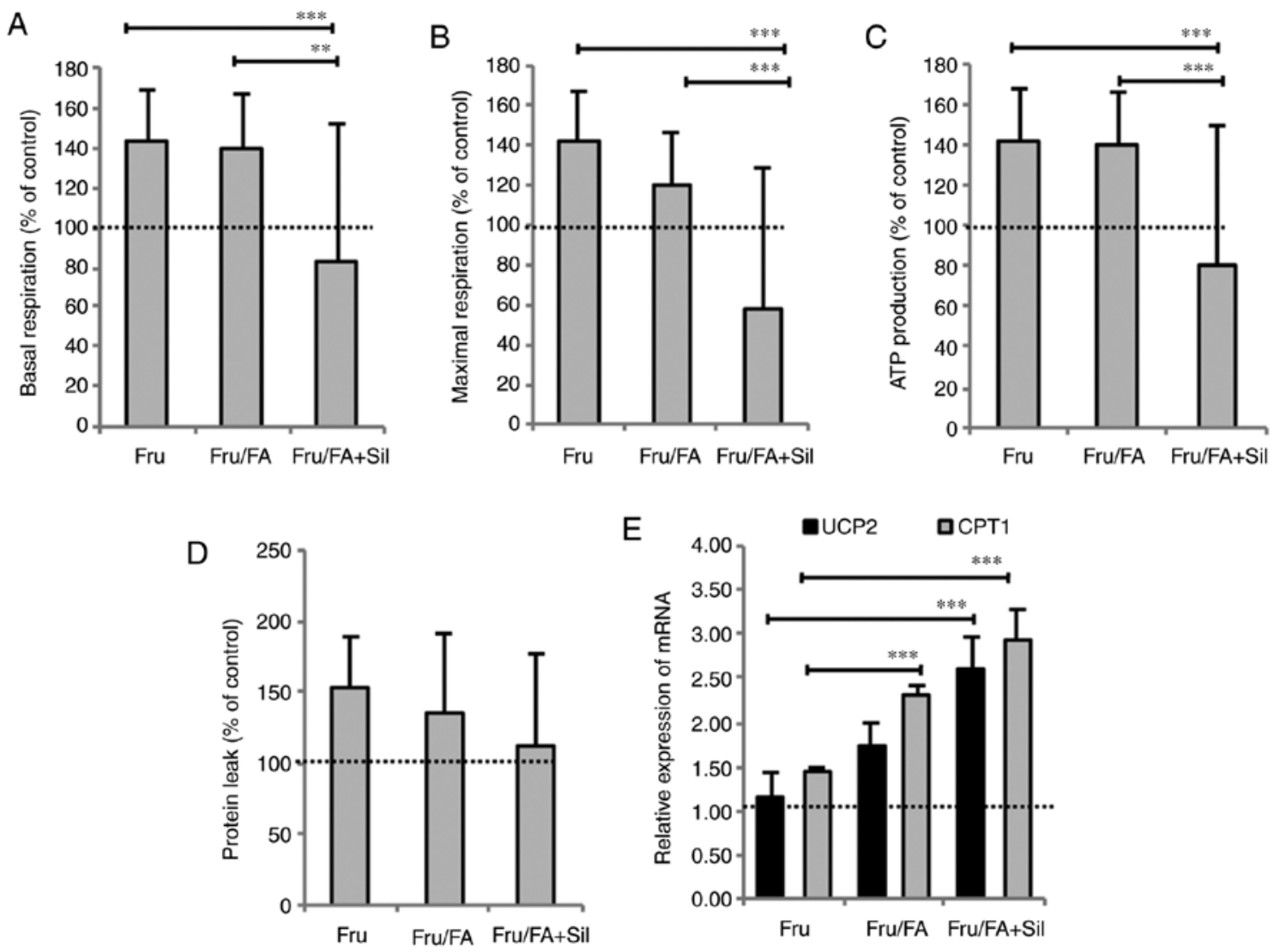

Figure 4. Silybin ameliorates mitochondrial dysfunction. Cells incubated with Fru/FA were then treated with silybin, and the following respiratory parameters were evaluated using the Seahorse XFe96 Extracellular Flux Analyzer: (A) Cell basal respiration, (B) cell maximal respiration, (C) ATP production and (D) proton leak (all presented as the OCR pmol/min/SRB labeling). Data are expressed as the mean \pm standard deviation of 14 separate experiments ( $=16$ ). (E) mRNA expression levels of UCP2 and CPT1 were evaluated by reverse transcription-quantitative polymerase chain reaction. Values are expressed as the mean \pm standard deviation from at least three independent experiments ( $\mathrm{n}=16$ for Seahorse experiments). ${ }^{* *} \mathrm{P} \leq 0.01$ and ${ }^{* * *} \mathrm{P} \leq 0.001$. Fru, fructose; FA, fatty acid; OCR, oxygen consumption rate; SRB, sulforhodamine B; CPT1, carnitine palmitoyltransferase 1; UCP2, uncoupling protein 2.

following observations: i) Enhanced steatosis; ii) maximal upregulation of ADRP and IKBIP expression levels; and iii) enhanced lipid peroxidation, ROS production and caspase 3-like activity, which are indexes of oxidative stress and apoptosis. The extensive damaging effect of Fru/FA combination was also evident when looking at the expression of miR-122, which is reportedly involved in the onset/progression of NASH (10).

Mitochondria are the main site for FA degradation, and steatotic hepatocytes typically enhance mitochondrial $\beta$-oxidation to limit excess fat accumulation (8). Accordingly, the mitochondrial proteins CPT1 and UCP2 were found to be overexpressed in cells treated with Fru/FA combination in the present study. Furthermore, basal and maximal mitochondrial respiration, as well as ATP production, were stimulated by Fru/FA combination in an attempt to compensate for the increased FA oxidation. Of note, the increase in oxidative stress due to the overactive $\beta$-oxidation may trigger proinflammatory pathways sustaining NAFLD progression. The results of the present in vitro study are in agreement with previous findings described in patients and animals $(29,30)$. While a 'high-fat' diet results in obesity, insulin resistance, and hepatic steatosis with minimal inflammation and no fibrosis, the 'Western' diet that is rich in fructose leads to steatosis associated with hepatic fibrosis, inflammation, oxidative stress and apoptosis (31).
The nutraceutical silybin is known as a general hepatoprotective, anti-steatotic agent $(21,25)$, which has provided promising results in animal and cellular models of NAFLD $(25,30)$, and in a number of clinical studies (32-34). Providing further insight into the effect of this agent, the present study demonstrated that silybin counteracted the metabolic dysfunctions caused by Fru/FA combination acting directly on hepatocytes. First, silybin reduced the large TG accumulation resulting from Fru/FA combination by downregulating the expression of PPAR $\gamma$, the main transcription factor for lipogenic genes. The hepatoprotective action of silybin was able to counteract in vitro the Fru/FA-dependent increase in terms of the following: i) IKBIP expression; ii) intracellular ROS production and lipid peroxidation; and iii) apoptosis rate. However, silybin was unable to alleviate the reduction in cell viability associated with exposure to Fru/FA combination. The action of silybin appears to be mainly dependent on its effects on mitochondria, with different mechanisms depending on the NAFLD grade (25). In our model mimicking a rather severe NAFLD, silybin exerts beneficial activity by inhibiting mitochondrial respiration, which is stimulated in steatosis progression as a consequence of an increased oxidative metabolism due to stimulation of anabolic pathways (35).

In conclusion, the cell model used in the present study, consisting of lipid-loaded hepatocytes mimicking the 
progression of NAFLD in vitro, offered new insights into the harmful steatogenic effects of fructose on liver cells and supports the hepatoprotective activity of silybin. Further studies can translate these results into long-term beneficial effects in the hope that the onset, progression and deterioration of NAFLD/NASH will be prevented or delayed in patients by using nutraceutical approaches.

\section{Acknowledgements}

The authors would like to thank Dr Moahamed Kalil, Dr Rita Fabbri and Dr Silvia Carestiato (DISTAV, Genova, Italy) for their experimental assistance.

\section{Funding}

The present study was supported by grants from the Compagnia di San Paolo (Torino, Italy) and the University of Genova, and funds from the Foundation for Science and Technology, Portugal (grant nos. PTDC/DTP-FTO/2433/2014, POCI-01-0145-FEDER-007440 and POCI-01-0145FEDER-016659).

\section{Availability of data and materials}

The datasets used and/or analyzed during the current study are available from the corresponding author on reasonable request.

\section{Authors' contributions}

All authors significantly contributed to this study. LV conceived and designed the study, analyzed and elaborated the data, and wrote the manuscript. EG carried out the qPCR analysis for miR-122 and spectrophotometric assay for FAS activity determination, and participated in writing the manuscript. FB performed cultures and treatments of $\mathrm{FaO}$ cells, fluorimetric and spectrophotometric assays, and qPCR measurements. GV carried out apoptosis determination and $\mathrm{O}_{2}$ consumption evaluation. PJO supplied the Seahorse XFe96 Extracellular Flux Analyzer and supervised the experiments for mitochondria analyses. VAS participated in $\mathrm{O}_{2}$ consumption analyses. AV participated in cell cultures and treatments, and critically revised the manuscript. PP participated in conceiving and designing the study, and critically revised the manuscript.

\section{Ethics approval and consent to participate}

Not applicable.

\section{Patient consent for publication}

Not applicable.

\section{Competing interests}

The authors declare that the research was conducted in the absence of any commercial or financial relationships that could be construed as a potential conflict of interest.

\section{References}

1. Vecchié A, Dallegri F, Carbone F, Bonaventura A, Liberale L, Portincasa P, Frühbeck G and Montecucco F: Obesity phenotypes and their paradoxical association with cardiovascular diseases. Eur J Intern Med 48: 6-17, 2018.

2. Mendez-Sanchez N, Cruz-Ramon VC, Ramirez-Perez OL, Hwang JP, Barranco-Fragoso B and Cordova-Gallardo J: New aspects of lipotoxicity in nonalcoholic steatohepatitis. Int $\mathrm{J}$ Mol Sci 19, 2018.

3. Listenberger LL, Ostermeyer-Fay AG, Goldberg EB, Brown WJ and Brown DA: Adipocyte differentiation-related protein reduces the lipid droplet association of adipose triglyceride lipase and slows triacylglycerol turnover. J Lipid Res 48: 2751-2761, 2007.

4. Feldstein AE, Werneburg NW, Canbay A, Guicciardi ME, Bronk SF, Rydzewski R, Burgart LJ and Gores GJ: Free fatty acids promote hepatic lipotoxicity by stimulating TNF-alpha expression via a lysosomal pathway. Hepatology 40: 185-194, 2004.

5. Neuschwander-Tetri BA: Hepatic lipotoxicity and the pathogenesis of nonalcoholic steatohepatitis: The central role of nontriglyceride fatty acid metabolites. Hepatology 52: 774-788, 2010.

6. Ter Horst KW and Serlie MJ: Fructose consumption, lipogenesis, and non-alcoholic fatty liver disease. Nutrients 9: pii: E981, 2017.

7. Gnocchi D, Massimi M, Alisi A, Incerpi S and Bruscalupi G: Effect of fructose and 3,5-diiodothyronine (3,5-T(2)) on lipid accumulation and insulin signalling in non-alcoholic fatty liver disease (NAFLD)-like rat primary hepatocytes. Horm Metab Res 46: 333-340, 2014

8. Grasselli E, Canesi L, Portincasa P, Voci A, Vergani L and Demori I: Models of non-alcoholic fatty liver disease and potential translational value: The effects of 3,5-L-diiodothyronine. Ann Hepatol 16: 707-719, 2017.

9. Moore KJ, Rayner KJ, Suárez Y and Fernández-Hernando C: The role of microRNAs in cholesterol efflux and hepatic lipid metabolism. Annu Rev Nutr 31: 49-63, 2011.

10. Dongiovanni $\mathrm{P}$, Meroni $\mathrm{M}$, Longo $\mathrm{M}$, Fargion $\mathrm{S}$ and Fracanzani AL: miRNA signature in NAFLD: A turning point for a non-invasive diagnosis. Int J Mol Sci 19, 2018.

11. Baselga-Escudero L, Souza-Mello V, Pascual-Serrano A Rachid T, Voci A, Demori I and Grasselli E: Beneficial effects of the Mediterranean spices and aromas on non-alcoholic fatty liver disease. Trends Food Sci Technol 61: 141-159, 2017.

12. Loguercio C, Tiso A, Cotticelli G, Blanco Cdel V, Arpino G, Laringe M, Napoli L, Piccinocchi G, Bonfrate L, Grattagliano I, et al: Management of chronic liver disease by general practitioners in southern Italy: Unmet educational needs. Dig Liver Dis 43: 736-741, 2011.

13. Loguercio C and Festi D: Silybin and the liver: From basic research to clinical practice. World J Gastroenterol 17: 2288-2301, 2011.

14. Vichai V and Kirtikara K: Sulforhodamine B colorimetric assay for cytotoxicity screening. Nat Protoc 1: 1112-1116, 2006.

15. Wolf BB, Schuler M, Echeverri F and Green DR: Caspase-3 is the primary activator of apoptotic DNA fragmentation via DNA fragmentation factor-45/inhibitor of caspase-activated DNase inactivation. J Biol Chem 274: 30651-30656, 1999.

16. Wiechelman KJ, Braun RD and Fitzpatrick JD: Investigation of the bicinchoninic acid protein assay: Identification of the groups responsible for color formation. Anal Biochem 175: 231-237, 1988.

17. Moreira AC, Branco AF, Sampaio SF, Cunha-Oliveira T, Martins TR, Holy J, Oliveira PJ and Sardão VA: Mitochondrial apoptosis-inducing factor is involved in doxorubicin-induced toxicity on H9c2 cardiomyoblasts. Biochim Biophys Acta 1842: 2468-2478, 2014

18. Grasselli E, Voci A, Canesi L, Goglia F, Ravera S, Panfoli I, Gallo G and Vergani L: Non-receptor-mediated actions are responsible for the lipid-lowering effects of iodothyronines in FaO rat hepatoma cells. J Endocrinol 210: 59-69, 2011.

19. Grasselli E, Voci A, Pesce C, Canesi L, Fugassa E, Gallo G and Vergani L: PAT protein mRNA expression in primary rat hepatocytes: Effects of exposure to fatty acids. Int J Mol Med 25: 505-512, 2010.

20. Goodridge AG: Regulation of the activity of acetyl coenzyme A carboxylase by palmitoyl coenzyme A and citrate. J Biol Chem 247: 6946-6952, 1972. 
21. Vecchione G, Grasselli E, Voci A, Baldini F, Grattagliano I, Wang DQ, Portincasa P and Vergani L: Silybin counteracts lipid excess and oxidative stress in cultured steatotic hepatic cells. World J Gastroenterol 22: 6016-6026, 2016.

22. Iguchi H, Kojo S and Ikeda M: Lipid peroxidation and disintegration of the cell membrane structure in cultures of rat lung fibroblasts treated with asbestos. J Appl Toxicol 13: 269-275, 1993.

23. Pfaffl MW: A new mathematical model for relative quantification in real-time RT-PCR. Nucleic Acids Res 29: e45, 2001.

24. Livak KJ and Schmittgen TD: Analysis of relative gene expression data using real-time quantitative PCR and the 2(-Delta Delta C(T)) method. Methods 25: 402-408, 2001.

25. Vecchione G, Grasselli E, Cioffi F, Baldini F, Oliveira PJ, Sardão VA, Cortese K, Lanni A, Voci A, Portincasa P and Vergani L: The nutraceutic silybin counteracts excess lipid accumulation and ongoing oxidative stress in an in vitro model of non-alcoholic fatty liver disease progression. Front Nutr 4: 42, 2017.

26. Deus CM, Zehowski C, Nordgren K, Wallace KB, Skildum A and Oliveira PJ: Stimulating basal mitochondrial respiration decreases doxorubicin apoptotic signaling in H9c2 cardiomyoblasts. Toxicology 334: 1-11, 2015.

27. Hudgins LC, Parker TS, Levine DM and Hellerstein MK: A dual sugar challenge test for lipogenic sensitivity to dietary fructose. J Clin Endocrinol Metab 96: 861-868, 2011.

28. Tetri LH, Basaranoglu M, Brunt EM, Yerian LM and Neuschwander-Tetri BA: Severe NAFLD with hepatic necroinflammatory changes in mice fed trans fats and a high-fructose corn syrup equivalent. Am J Physiol Gastrointest Liver Physiol 295: G987-G995, 2008.
29. Reina M and Martinez A: Silybin and 2,3-dehydrosilybin flavonolignans as free radical scavengers. J Phys Chem B 119: 11597-11606, 2015

30. Rosso N, Marin V, Giordani A, Persiani S, Sala F, Cavicchioli L, Rovati LC and Tiribelli C: The pros and the cons for the use of silybin-rich oral formulations in treatment of liver damage (NAFLD in particular). Curr Med Chem 22: 2954-2971, 2015.

31. Ameer F, Scandiuzzi L, Hasnain S, Kalbacher H and Zaidi N: De novo lipogenesis in health and disease. Metabolism 63: 895-902, 2014.

32. Abenavoli L, Greco M, Nazionale I, Peta V, Milic N, Accattato F, Foti D, Gulletta E and Luzza F: Effects of Mediterranean diet supplemented with silybin-vitamin E-phospholipid complex in overweight patients with non-alcoholic fatty liver disease. Expert Rev Gastroenterol Hepatol 9: 519-527, 2015.

33. Federico A, Conti V, Russomanno G, Dallio M, Masarone M, Stiuso P, Tuccillo C, Caraglia M, Manzo V, Persico M, et al: A long-term treatment with silybin in patients with non-alcoholic steatohepatitis stimulates catalase activity in human endothelial cells. In Vivo 31: 609-618, 2017.

34. Wah Kheong C, Nik Mustapha NR and Mahadeva S: A randomized trial of silymarin for the treatment of nonalcoholic steatohepatitis. Clin Gastroenterol Hepatol 15: 1940-1949.e8, 2017.

35. Satapati S, Kucejova B, Duarte JA, Fletcher JA, Reynolds L, Sunny NE, He T, Nair LA, Livingston KA, Fu X, et al: Mitochondrial metabolism mediates oxidative stress and inflammation in fatty liver. J Clin Invest 125: 4447-4462, 2015. 